\title{
Extraction, Identification, and Quantification of Harmala Alkaloids in Three Species of Passiflora
}

\author{
Abigail Frye and Catherine Haustein \\ Department of Chemistry \\ Central College \\ 812 University \\ Pella, lowa 50219 USA
}

Accepted: December 27, 2007

\begin{abstract}
Harmala alkaloids are a common plant extract with a number of reported uses including as stimulants and monoamine oxidase (MAO) inhibitors. Their reported activity has led some researchers to identify them as the principal active constituent in passion flowers, an abundant plant which has been identified to have a number of pharmaceutical uses of its own. Harmalas are commonly extracted using chloroform; however, in this case, a green extraction process using ethyl acetate and sodium bicarbonate was applied. Analysis of the harmala alkaloids in Passiflora caerulea, Passiflora incarnata and Passiflora "Coral Glow" was performed quantitatively using the HPLC. Comparison of HPLC results from plant extracts to results from standard solutions concluded that harmol and harmine were present in minor amounts in Passiflora incarnata, harmine was present in large amounts in Passiflora caerulea, and no significant amounts of harmala alkaloids were found in Passiflora "Coral Glow". The extraction process and HPLC analysis also revealed the presence of the flavonoid derivative Vitexin in Passiflora incarnata. Vitexin was present in relatively large amounts, and as a flavonoid derivative, the compound may have powerful antioxidant activity.
\end{abstract}

\section{INTRODUCTION}

Plants can be an excellent source of pharmaceutical compounds, but their molecules are often complex or difficult to synthesize. For example, the chemotherapy drug paclitaxel, commonly known as Taxol $^{\circledR}$, originally discovered in the tree bark of the Pacific Yew tree called Taaxus brevifolia, is very difficult to synthesize. The synthesis process is expensive and laborious. In fact, since its discovery in the early 1960s, only three complete syntheses have been carried out. The Holton group and the Nicolaou group published their syntheses in 1994 and the Danishfesky group published an additional synthesis in 1996 [1]. The impediments in the synthesis process made the extraction of the compound from natural sources critical, and led researchers to search for and eventually discover a closely related analogue in the leaves of a European species of ornamental shrub called Taxus baccata. Today, Taxol $^{\circledR}$ is an important drug commonly used to treat ovarian, breast, and non-small cell lung cancer.

Another type of plant with pharmaceutically significant extracts is passion flowers. Of the approximately 500 Passiflora species, Passiflora incarnata has been the most extensively studied for its pharmacological effects. Multiple studies have confirmed that it's most powerful use is 
as a sedative or as an antispasmodic, and often in combination with other drugs. A fluid extract from Passiflora incarnata "significantly prolonged sleeping time" when administered to rats [2]. Passiflora extracts induce a "normal" sleep: patients fall asleep naturally and can be awakened as usual. Additionally, there are no negative side effects. The sedative action of Passiflora is increasingly important in our 24/7 society. Today excessive daytime sleepiness and insomnia affect approximately 60 million Americans [3]. Sleep deprivation and untreated sleep disorders cause an array of negative outcomes from poor work performance to car crashes. Although an average human spends a third of their life sleeping and a human being can live longer without food than without sleep, researchers still do not completely understand it [3].

As an antispasmodic, Passiflora was traditionally used in cases of severe spasm (e.g., tetanus), to abort an epileptic attack, in children to control the spasmodic coughing associated with whooping cough, and to alleviate the spasms that accompany menstrual pain [4]. Bergner [4] also indicates that Passiflora extracts are useful in the treatment of the manic phase of bipolar disorder, the symptoms associated with neuralgia and shingles, the fretfulness of teething children, and other general pain. Additionally, Passiflora has been used to control abnormal cardiac arrhythmias and tension-related asthma, and as an anxiolytic, muscle relaxant, antidepressant, and adaptogen [5, 6]. In all cases, Passiflora is especially well-suited for the treatment of pediatric and geriatric patients. It is most consistent and effective in the treatment of the weak, fragile, or exhausted patient.

Despite the abundance and known pharmacological effects of passion flowers, a relatively small number have been properly investigated. Since the late 1960s, only about 40 species have been phytochemically researched $[5,6]$. A few species, notably $P$. incarnata and $P$. edulis, have even been researched extensively, yet researchers have not been able to identify the single active constituent responsible for their medicinal effects. Flavonoids and alkaloids are most commonly cited as the active constituents [4-7]. However, the presence of harmala alkaloids in the medicinally significant Passiflora incarnata is

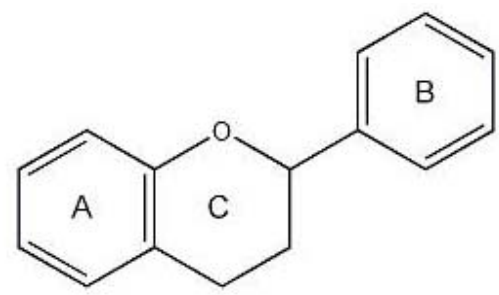

Figure 1. Basic structure of flavonoids.

still debatable [5-6]. This has caused researchers to question the importance of harmala alkaloids in relation to the therapeutic effects of passion flowers [4]. However, the pharmaceutical importance of both flavonoids and harmala alkaloids is not in question.

The term flavonoids is used to describe a wide variety of compounds found in plants that give them their colorful pigments. The analysis of these compounds has proven to be valuable in the identification of several species of Passiflora. There is strong experimental evidence of flavonoids' ability to modify the body's reaction to allergens, viruses, and carcinogens. They are perhaps best known for their powerful antioxidant activity. Two flavonoid derivatives that are typical of Passiflora incarnata, are vitexin and isovitexin. Vitexin is "known to be a potent inhibitor of thyroid peroxidase and also to inhibit fast reacting fibres" [7].

Harmala alkaloids are a group of $\beta$ carboline alkaloids found in significant amounts in many plant families. These alkaloids have been identified as stimulants and monoamine oxidase (MAO) inhibitors. Other pharmacological activities such as antihypertensive, hallucinogenic, and antidepressant effects have been also been attributed to the harmala alkaloids [5-6]. Harmine, in particular, was originally used to treat Parkinson's disease, but also has been found to have vasorelaxant, anti-tumor, and anti-HIV effects [8]. More recently, the antileishmanicidal activities of Harmine have been studied more closely. Leishmaniasis is a macrophage-associated disease spread by the bite of infected sand flies. In the past, there has been speculation regarding the pharmacological effects of harmala alkaloids, and the findings that indicated the 


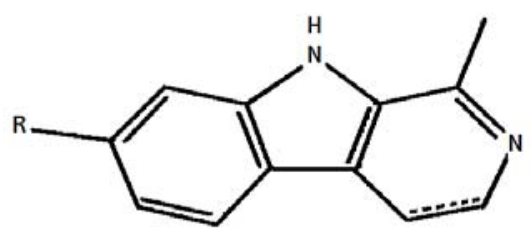

$$
\mathrm{R}=\mathrm{H}, \mathrm{OH}, \mathrm{OCH}_{3}
$$

Figure 2. Basic Structure of harmala alkaloids.

compounds possessed cytotoxic properties. However, Splettstoeser et al. [9] report that harmala alkoloids "have been shown to protect neurons against the excitotoxic effects of dopamine and glutamate."

As is the case with Taxol $^{\circledR}$, harmala alkaloids are difficult to synthesize. However, harmala alkaloids are easy to extract from species of passion flowers. A previous study concluded that one or more harmala alkaloid is present in a variety of Passiflora species [5-6]. They are commonly isolated from plant materials by extraction with petroleum ether and chloroform [10-11] or methanol often combined with the Soxhlet extraction [12]. Other studies have not focused on the direct extraction of the harmala alkaloids from passion flowers; however, Lewis developed an effective extraction method using ethyl acetate, which is not as toxic as chloroform [13].

A problem with the extraction of Taxol $^{\circledR}$ from natural sources is that the Pacific yew tree, which was the original source, is an environmentally protected species, and is also one of the slowest growing trees in the world. The isolation process results in killing the tree, and six one-hundred-year-old trees would have to be used in order to extract enough taxol to treat only one patient [1]. Although a closely related analogue called baccatin III has been discovered, the extraction and following chemical elaboration of the compound to taxol is extremely laborious. However, this is not the case with the extraction of harmala alkaloids and isoflavonoids from passion flowers. Passion flowers are abundant and the extraction process is relatively simple. There are approximately 500 known species of passion flowers. It is estimated that nearly
95 percent of all passion flowers originated in the tropical rain forests of South America, while the other 5 percent came from North America, Asia and Australia. They can now be found growing wild on six continents and many islands worldwide. Although most species thrive in tropical climates, some can survive much colder conditions, even temperatures below freezing for extended periods of time, such as during the winter season [14]. These characteristics make the plant easy to grow and consequently an attractive plant to study.

The three species of passion flowers that were used in this study are Passiflora caerulea, Passiflora incarnata, and Passiflora "Coral Glow." P. caerulea and $P$. incarnata usually have blue and white flowers, but there is a possibility for variation. The only noticeable difference between the two species is that $P$. incarnata has a wrinklier corona. "Coral Glow" passion vines have deep, rich coral red-pink flowers that some sources characterize as hot pink.

\section{EXPERIEMENTAL}

\section{a. Extraction}

The basis for the extraction of harmala alkaloids was the acidification of the harmalas followed by the removal of impurities with organic solvent, and neutralization followed by the removal of the harmala into ethyl acetate.

The plant extract was obtained by cutting up the stems, leaves, and tendrils of the passion flower plants and allowing them to dry in a dessicator. Approximately 15 grams of dried plant material was ground using a small coffee grinder and mixed with five times their weight of an acetic acid 


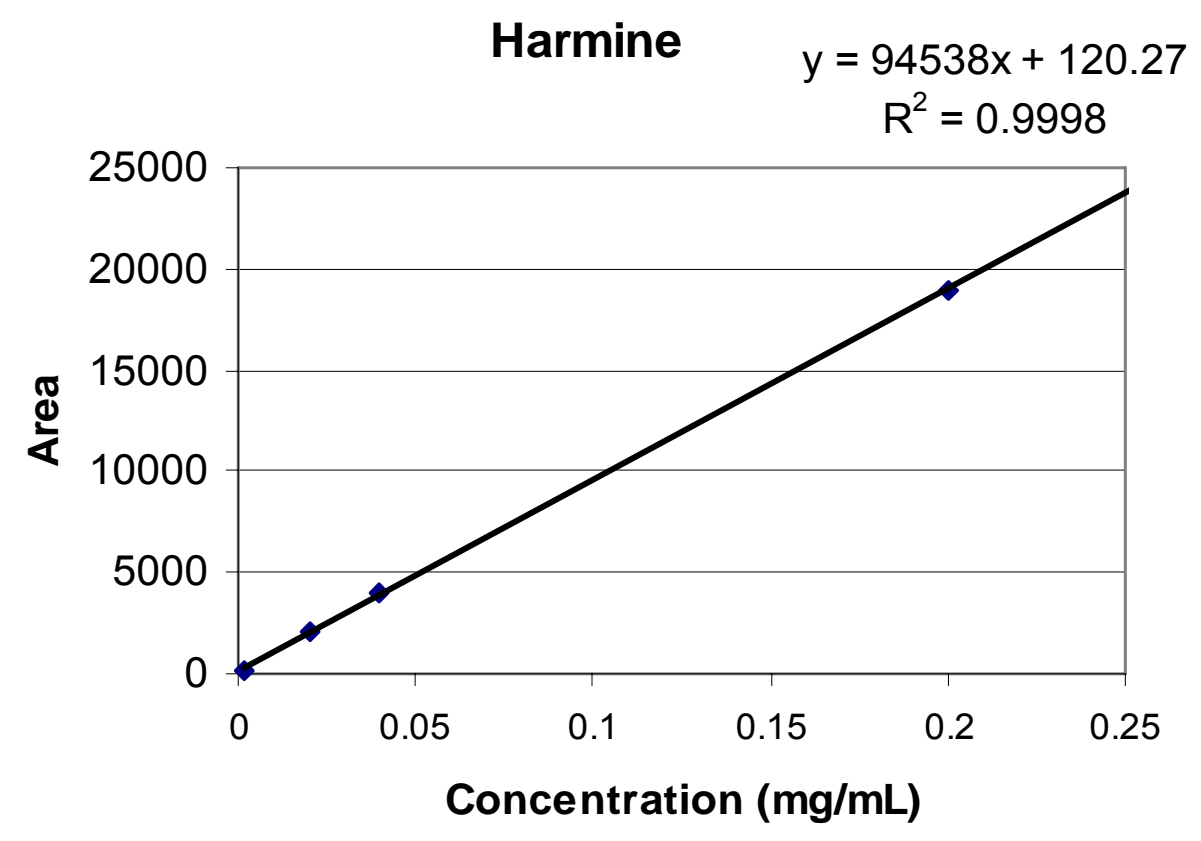

Figure 3. Calibration curve for Harmine.

solution containing 30 grams of acetic acid per liter of water. The acetic acid and plant material slurry was stirred for five minutes before being filtered using a Bucher funnel and Whatman 4 filter paper. Two washings of the plant material with the acetic acid solution were performed. The aqueous plant extract solution was washed three times with $50 \mathrm{~mL}$ of petroleum ether and 50 $\mathrm{mL}$ of ethyl acetate using a seperatory funnel to remove the organic impurities. The bottom layer was collected and a saturated sodium bicarbonate solution was added to neutralize the acid. The resultant solution was extracted three times with $100 \mathrm{~mL}$ ethyl acetate to remove the aqueous impurities. The top layer was collected and excess sodium sulfate was added to ensure the removal of excess water. The "dry" solution was poured through a glass funnel and cotton ball filter into a roundbottom flask of known mass to filter out any remaining solids. The solvent was then removed using rotary evaporation using an aspirator. After the resulting residue had been pumped to dryness, it was weighed.

Preparation of the known solutions of the five harmala alkaloids and the two flavonoid derivatives was done in a similar manner. A known mass of the standard was dissolved in a saturated sodium bicarbonate solution and then extracted with ethyl acetate. In the case of the harmala alkaloid standards, approximately one-tenth of a gram of standard was mixed with $100 \mathrm{~mL}$ sodium bicarbonate solution, and then extraceted with $25 \mathrm{~mL}$ portions ethyl acetate four times. In accordance with the procedure used for the plant extracts, excess sodium sulfate was added to this solution before pouring it through a cotton ball filter and eventually connecting it to the rotary evaporator followed by the pump to eliminate all liquid solution. The flavonoid derivatives were for a purely qualitative purpose, so a similar procedure was used on a much smaller scale, and no quantitative measurements were recorded.

After determining the mass of the residue, it was dissolved in methanol for HPLC analysis. The plant extract samples were passed through a Chrom Tech $0.5 \mu \mathrm{m}$ disposable filter to remove large particles that would wear down the injection system of the HPLC.

b. HPLC

An Agilent 1100 HPLC with UV-vis detection capabilities and a $20 \mathrm{~mL}$ injection 


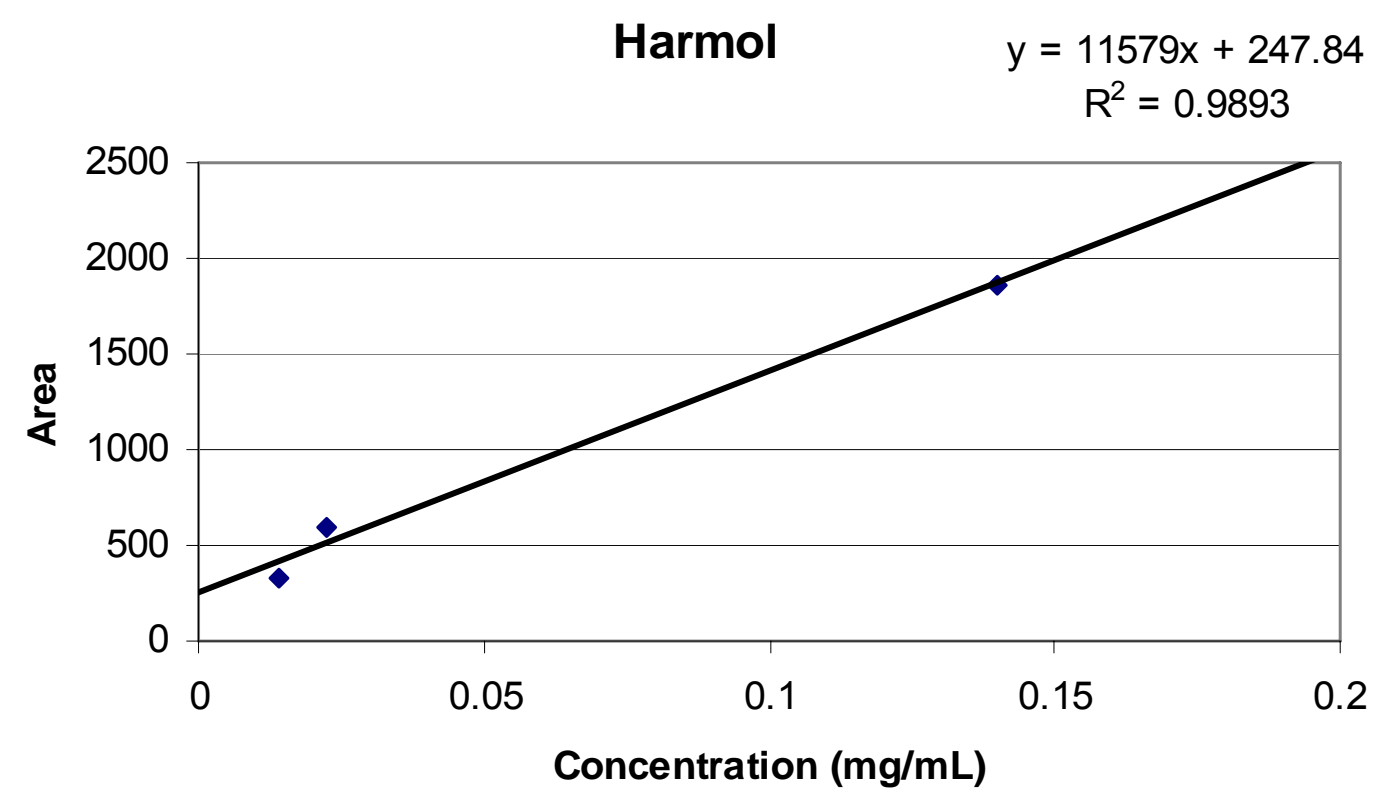

Figure 4. Calibration curve for Harmol.

loop was used. The wavelength used during the analysis was $340 \mathrm{~nm}$. A Phenomenex Luna column measuring $250 \times 4.60 \mathrm{~mm}$ and with $5 \mathrm{u} \mathrm{C18}$ stationary phase was used. The column was heated and maintained at $25^{\circ} \mathrm{C}$ with a Phenomenex TS - 130 heater. Elution was done with a methanol water gradient at a flow rate of $1.0 \mathrm{~mL} / \mathrm{min}$. The level of methanol was increased from $0 \%$ to $100 \%$ over a ten minute period. This combination has proven to produce the most consistent results. The HPLC results were used for identification and quantification of the harmala alkaloids present in the species of passion flower by comparing known solutions to the plant extracts.

\section{RESULTS \& DISCUSSION}

Standard solutions of harmine, harmol, harmane, and harmolol were prepared and analyzed; however calibration curves were only made for harmine and harmol, because they were the only harmala alkaloids identified located in the plant extracts of $P$. incarnata and $P$. caerulea. The calibration curves were created by performing the extraction process on a known amount of the standard, and then performing a number of dilutions. A 1:100,
$1: 10$ and $1: 5$ dilutions were made for the harmine standard, and 1:10, 8:50 dilutions were made for the harmol standard. The concentrations of the dilutions were then plotted against the area of the resultant peak (see Figures $3-4$ ).

The results are shown in Table 1 . The $P$. incarnata extracts had an average value of $0.031 \mathrm{mg} / \mathrm{g}$ harmol and an average of $0.00935 \mathrm{mg} / \mathrm{g}$ harmine. The $P$. caerulea samples had an average of $0.098 \mathrm{mg} / \mathrm{g}$ harmine.

Retention times were used to identify the compounds present in the Passiflora extracts. The peaks of the plant extracts were compared to the standard peaks. The relative retention times for the harmala alkaloids, harmane, harmine, harmol, and harmolol, and the flavonoid derivatives, isovitexin and vitexin, were supported by literature values reported [5-7].

The chromatograms Passiflora incarnata both showed a large peak with retention times at 3.990 and 3.988 minutes and two smaller peaks at 4.641 and 4.686 minutes and 5.332 and 5.383 minutes. The three peaks were identified as the flavonoid derivative vitexin, and the harmala alkaloids harmol and harmine, respectively. Abourashad, et. al. [5-6] report finding measurable amounts of harmane, harmol, 


\begin{tabular}{|c|c|c|c|}
\hline \multicolumn{2}{|c|}{ Passiflora Incarnata } & \multicolumn{2}{|c|}{ Passiflora Caerulea } \\
\hline Harmine Peak Area & $\begin{array}{l}\text { Concentration of } \\
\text { Harmine in plant } \\
\text { extract (mg/g) }\end{array}$ & Harmine Peak Area & $\begin{array}{l}\text { Concentration of } \\
\text { Harmine in plant } \\
\text { extract (mg/g) }\end{array}$ \\
\hline 209.59 & 0.0057 & 3600.37 & 0.0935 \\
\hline 382.79 & 0.013 & 4242.67 & 0.102 \\
\hline Harmol Peak Area & $\begin{array}{l}\text { Concentration of } \\
\text { Harmol in plant } \\
\text { extract (mg/g) }\end{array}$ & & \\
\hline 246.79 & 0.0122 & & \\
\hline 334.82 & 0.0493 & & \\
\hline
\end{tabular}

Table 1. Peak areas and the corresponding concentration of harmala alkaloid in the plant extract.

harmine, harmaline, and harmalol in $P$. incarnata plant extract. Grice, et.al. [7] detected harmane and harmine in $P$. incarnata extracts along with vitexin and isovitexin.

Determination of the area of known concentrations of standard solutions was used to calculate the concentrations present in the plant extracts. Two extractions from $P$. incarnata were completed and the results varied greatly. There was an average of $.031 \mathrm{mg} / \mathrm{g}$ of harmol in Passiflora incarnata, with a range of $.037 \mathrm{mg} / \mathrm{g}$. There was an average of $.00935 \mathrm{mg} / \mathrm{g}$ of harmine present, with a range of $0.00730 \mathrm{mg} / \mathrm{g}$ as well. The largest peak was qualitatively identified as vitexin. The levels of the harmala alkaloids varied widely between the two samples of Passiflora incarnata. This was not completely unexpected based on the data reported by Grice, et al. [7] that the levels of harmala alkaloids vary based on the stage of development the plants were harvested in. The stems, leaves, and tendrils used for the extraction were picked at different times throughout the year.

The chromatograms of the $P$. caerulea plant extract both showed a large peak at at 5.200 and 5.262 minutes identified as harmine by comparison to
HPLC analysis of a standard harmine solution. The analyses also showed smaller and broader peaks at 4.321 and 4.431 minutes and 4.730 and 4.827 minutes. These peaks could not be identified based on comparison with the standard harmala solutions of harmane, harmine, harmol, and harmolol.

The $P$. caerulea results were more reproducible, which following the theory reported by Grice, et al. [7] that harmala alkaloids levels in passion flowers vary based on when the plant was harvested is to be expected. The Passiflora caerulea stems, leaves, and tendrils used for the extractions were picked within the same week. Using the area of the peak, the concentration of harmine in the plant extract could be calculated. The average harmine level in Passiflora caerulea was $0.098 \mathrm{mg} / \mathrm{g}$ with a range of $0.0085 \mathrm{mg} / \mathrm{g}$. This is much higher level of harmala alkaloid as compared to the levels found in the Passiflora incarnata samples. This was an unexpected result based on the current literature since Abourashad et al [5-6] report higher levels of harmine in $P$. incarnata as compared to $P$. caerulea.

No quantifiable amounts of harmala alkaloids were detected in Passiflora "Coral 
Glow." Abourashad et al/ [5-6] report the harmala levels detected in 104 samples of Passiflora, and 50 of the samples had no detectable levels of harmala alkaloids. Cavin \& Rodriguez [15] state that harmala alkaloids frequently occur in such small concentrations that they have not been quantified, which may be a reason that their presence in species of Passiflora is at times disputed and not always reproducible.

\section{CONCLUSIONS}

The results indicate that $P$. incarnata and $P$. caerulea are potential sources for harmala alkaloids. For harmine production $P$. caerulea would be the plant of choice, and for harmol production, $P$. incarnata would be the best option. However, $P$. incarnata appears to be even a better source for the flavonoid vitexin as opposed to harmala alkaloids.

$P$. incarnata is considered the most pharmaceutically significant species of Passiflora; however according to this research $P$. Caerulea was the better source of harmine and $P$. incarnata did not have a large amount of harmala alkaloids. This contributes to the data suggesting that harmala alkaloids are not the active constituent of Passiflora. The relatively large peak corresponding to the isoflavonoid vitexin found in $P$. incarnata may provide an area of future study regarding the chemical composition and the active constituent(s) of Passiflora extracts.

Based on the results of this research, it appears that the green extraction technique using ethyl acetate as opposed to chloroform is a valid method for the extraction of harmala alkaloids and possibly flavonoids. However, further study and comparison to results using chloroform is necessary to confirm this. Comparison to past extraction results using chloroform is unreliable based on the hypothesis that the amount of harmalas varies based on the stage of development of the plant when it was harvested.

\section{REFERENCES}

1. Edwards, N. (1996). Taxol. Retrieved November 11, 2005, from http://www.bris.ac.uk/Depts/Chemistry/ MOTM/taxol.htm
2. Speroni, E. \& Minghetti, A. (1988). Neuropharmacological Activity of Extracts from Passiflora incarnata. Planta medica. 488-491.

3. Weaver, Eris. (2005, January). A good night's sleep. Library Journal. 130, 6567.

4. Bergner, Paul. (1995, Spring/Summer). Passion flower. Medical Herbalism: A Journal for the Clinical Practitioner 7(1/2):13-15.

5. Abourashad, Ehab, Vanderplank, John, \& Khan, Ikhlas. (2003). High-speed extraction and HPLC fingerprinting of medicinal plants I. Application to Passiflora Flavonoids. 40 (2), 81-91.

6. Abourashad, Ehab, Vanderplank, John, \& Khan, Ikhlas. (2003). High-speed extraction and HPLC fingerprinting of medicinal plants II. Application to harman alkaloids of genus Passiflora. 41(2), 100-106.

7. Grice, I., Ferreira, L, \& Griffiths, L. (2001). Identification and simultaneous analysis of harmane, harmine, harmol, isovitexin, vitexin in Passiflora incarnata extracts with a novel HPLC method. Jounral of Liquid Chromotography \& Related Technologies. 24 (16), 25132523.

8. Sanchaita, L., Swapan, P., Sibabrata, M., Santu, B., \& Mukul, K. B. (2004, April). Harmine: Evaluation of its antileishmanial properties in various vesicular delivery systems. Journal of Drug Targeting. 12(3), 165-175.

9. Splettstoesser, F., Bonnet, U., Wiemann, M., Bingmann, D., \& Busselberg, D. (2005). Modulation of voltage-gated channel currents by harmaline and harmane. British Journal of Pharmacology. 144, 52-58.

10. Dhwan, K, Kumar, S, \& Sharma, A. (2002). Comparative anxiolytic activity profile of various preparations of Passiflora incarnata Linneaus: A comment on medicinal plants' standardization J. Alternative and Complemantary Medicine. 8, 283-291.

11. Kartal, M, Altun,S, \& Kurucu, S. (2003). HPLC Method for the analysis of harmol, harmalol, harmine and harmaline in the seeds of Peganum harmala L. J. Pharm. Biomed. Anal. 31, 263-269. 
12. Xie, J., Lili,Z., \& Xu, X.. (2002). Affinative separation and on-line identification of antitumor components from Peganum nigellastrum by coupling a chromatographic column of target analogue imprinted polymer with mass spectrometry. Amal. Chem., 74, 23522360.

13. Lewis, Jeremy, Shriver, James, \& Haustein, Catherine. The free base extraction of harmalas from Syrian Rue.
(2005). See

www.central.edu/chemistry/cathycv.htm

14. Vanderplank, John. (2000). Passion flowers. ( $3^{\text {rd }}$ ed.). Cambridge, MA: The MIT Press.

15. Cavin, Janice Clymer \& Rodriguez, Eloy. (1988). High-performance liquid chromotographic identification of simple carboline alkaloids in specimens of Heliconiini butterflies. Journal of Chromotography. 447 (2), 432-435.

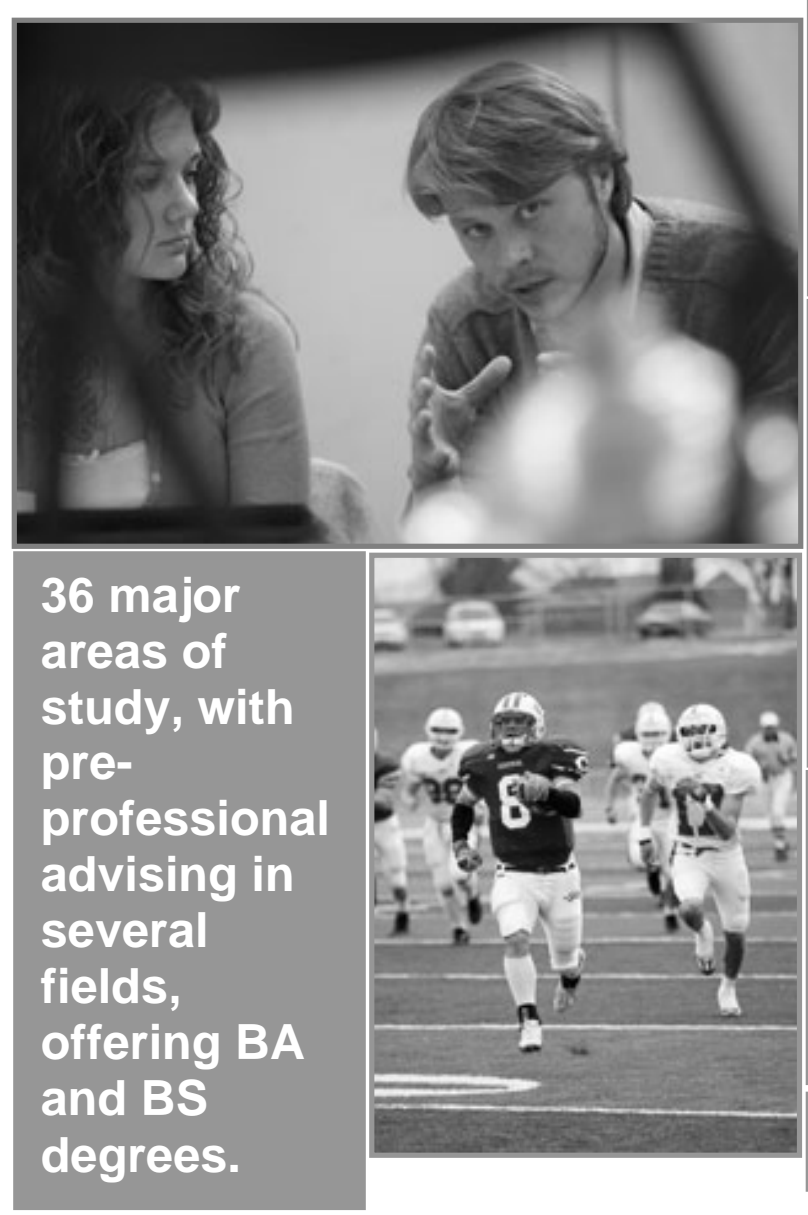

Central College, founded in 1853 , is a private fouryear liberal arts college affiliated with the Reformed Church in America.

\begin{tabular}{l} 
Located in Pella, lowa, \\
Central is home to 1600 \\
students from lowa and \\
many countries, and has 89 \\
full-time faculty members. \\
WWW.Central.edu \\
\hline
\end{tabular}

